\title{
Management of Pollutants in Industries: A Case Study
}

\section{Seyed Ebrahim Vahdat ${ }^{*}$, Rohollah Askarpour, Pedram Keyhany, Yones Rahimi, Hadi Soflaei}

Department of Engineering, Bandar Abbas Branch, Islamic Azad University, Bandar Abbas, Iran

\section{Email address:}

e.vahdat@iauamol.ac.ir (S. E. Vahdat), askarpour2002@yahoo.com (R. Askarpour), p.keyhany@gmail.com Pedram Keyhany(P. Keyhany), younesrahimi55@gmail.com (Y. Rahimi), hadi.soflaei@gmail.com (H. Soflaei)

\section{To cite this article:}

Seyed Ebrahim Vahdat, Rohollah Askarpour, Pedram Keyhany, Yones Rahimi, Hadi Soflaei. Management of Pollutants in Industries: A Case Study. Journal of Investment and Management. Vol. 4, No. 4, 2015, pp. 113-118. doi: 10.11648/j.jim.20150404.13

\begin{abstract}
In this paper, using fuzzy logic, a model is presented to monitor region wise industrial pollutants in pyrometallurgy industries. The model has been used in a case study that will determine which industry, in which region, producing which and how much pollutants, is ecologically compatible. To assess the ecological compatibility, first, the sets of industries, regions, pollutants and ecology compatibility were defined. Then, to calculate the membership degree of the members of the ecology compatibility set, the membership function of ecology compatibility was defined. By ranking different industries in various regions, producing different pollutants, as continuous figures, the ecological compatibility of these industries was accurately compared. Given the degree of ecological compatibility in a region, the type of pollutant and the related industry, identification of the lowest degree of ecological compatibility was the first priority of this case study. Results of the conducted case study, without considering the region coefficient, show that in December 2005 , member $\mathrm{C}_{241}$, with an ecological degree of compatibility equivalent to 0.0559 , had the most critical condition in producing carbon dioxide. However, in the same period in 2005 , on considering the region coefficient, member $\mathrm{C}_{121}$, with an ecological degree of compatibility equivalent to 0.0655 , showed the most critical condition as far the production of carbon dioxide was concerned.
\end{abstract}

Keywords: Fuzzy Logic, Monitoring, Pyrometallurgy Industries

\section{Introduction}

In considering capabilities for sustainable development, ecological, economical, and social and industrial concerns have rapidly become the most important challenges in the twenty first century. Due to the existence of many pollutant producers, each producing some kind of pollutants in various regions with different pollution levels, the simultaneous consideration of all the pollutant producers for the purpose of pollution management and control becomes a difficult task. However, through prioritizing them in terms of ecological compatibility as continuous figures, it can be determined that which industry, in which region, producing which and how much pollutants, should be in the priority of investigation. The comparison model of various indices, based on fuzzy logic, shows the relativity of various features, defines a set for each feature, and determines the utility rate of each variable to provide the desired feature by a degree between 0 and 1. This value, as the awarded degree of the desired variable, is measured compared to the mentioned feature. On this basis, desirability degree of 0 would mean that the desired feature is not provided for the desired variable, or the desired variable is not desirable for the desired feature at all. Similarly, desirability degree of 1 means the desired feature is provided for the desired variable or the desired variable is desirable for the desired feature. Following the same reasoning, a desirability degree between 0 and 1 would mean that the desired feature is provided to some degree for the desired variable or the desired variable is to some degree desirable for the desired feature.

Researchers have used fuzzy logic to study the pollutants in the environment. Ref [1] used fuzzy logic in studying the sustainable development of iron and steel industry in the context of ecology in Iran. Ref [2] ranked air pollutants in five regions of Tehran (Iran), however, they did not consider the effect of the pollutants, already existing in the studied regions, in their model. In other words, the effect of produced pollutants is different for less polluted and more polluted regions, which must be considered in any such study. Ref [3] used fuzzy logic to predict the ozone concentration and matched their model with the data obtained from Weather Bureau of Canada. Ref [4] used the fuzzy logic to quantify photochemical model and predict pollutants and matched their model with the data from Weather Bureau of 
Hong Kong. Ref [5] applied chemo-metrics, based on fuzzy logic principles, in his environmental studies. Ref [6] used fuzzy logic for the air conditioning system of long tunnels. Ref [7] presented a model based on fuzzy logic to determine the extent of water pollution and then matched it with the data of Water Department of Eber Lake in Turkey.

A consideration of the cited literature shows that a comprehensive model to study the degree of ecological compatibility of various industries, especially taking into account the district effect is yet to be attempted. In this paper, the ecological compatibility feature has been used, so that at a given time, the degree of ecological compatibility of any given industry in any given region in the production of any given pollutant can be monitored, relatively and quantitatively. On the basis of the minimum degree of ecological compatibility, priority in studying and monitoring different industries in various regions, producing different pollutants, can be presented.

In this paper, the fuzzy logic has been used to determine the degree of ecological compatibility of industries in various regions of the world. The set of pollutants can exist in the solid state (such as dust, soot, and lead dust); liquid (such as mercury dissolved in water), gas (such as carbon, carbon dioxide, methane), and also in the form of the sound and wave (such as the radioactive rays). The set of regions in the world is formed from the set of different continents (Asia, Europe, Africa, America and Oceania), and the set of continents from the set of various countries (Russia, China, India, Iran...). Similarly, the set of countries is obtained from the set of different regions (urban, rural, industrial areas, etc.). The set of pollutant producers consist of the set of domestic industries (HVAC systems,...), transportation industries (automobile,...), hydrometallurgy industries (sewage,...), pyrometallurgy industry (iron and steel manufacturing industries, copper, lead, zinc and aluminium, etc.). In the present study, the sizes of data sets have been reduced for the sake of simplification. Accordingly, from the set of pollutants only carbon dioxide has been considered. Similarly, from the set of industries only pyrometallurgy industries, from the set of pyrometallurgy industries only iron, steel, aluminium, lead and zinc, and from the set of regions only one country in each region, namely the Far East, the Middle East, Europe and America, have been considered in this study for calculation and comparison of ecological compatibility degree for each case.

\section{Methods}

To determine the ecological compatibility, first, the sets of industries, regions, pollutants and ecology compatibility were defined. Then, to calculate the membership degree of the members of the ecology compatibility set, the membership function of ecology compatibility was defined. Figure 1 shows the procedure for implementing the method used in this study.

\section{Definition of the sets}

In this study, to assess the ecological compatibility degree of pyrometallurgy industries in various regions using fuzzy logic, three sets have been defined and examined as followings:

Set M: This set includes the industries producing iron and steel, aluminium, copper, lead, zinc, creating pollutants such as carbon dioxide, which are expressed by Eq. (1). Set M can contain $\mathrm{m}$ members, and $\mathrm{m}_{\mathrm{i}}$ is the $\mathrm{i}^{\text {th }}$ metallurgy industry being studied:

$$
\mathrm{M}=\left\{\mathrm{i} \in \mathbb{N}, \mathrm{i} \in[1, . ., \mathrm{m}], \mathrm{m}_{\mathrm{i}}\right\}=\left\{\mathrm{m}_{\mathrm{i}}\right\}
$$

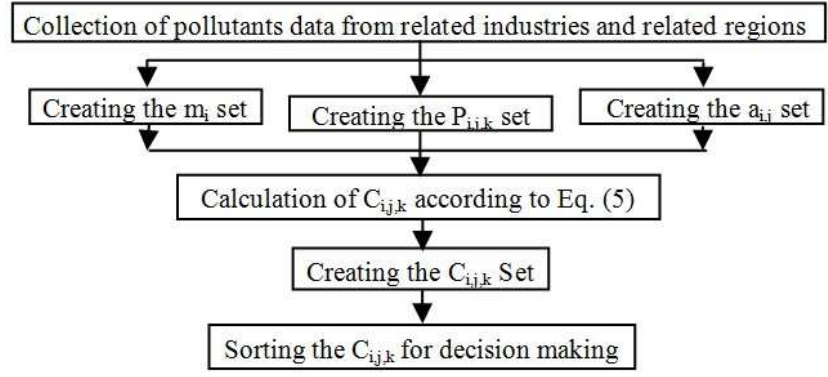

Figure 1. Fuzzy inference algorithm for determination of the ecological compatibility degree.

Set A: This set includes the regions in which pollutants are produced, and is defined and evaluated based on Eq. (2). Set A can be the set of regions enclosed in world pyrometallurgy factories such as steel mills in Isfahan (Iran), Hamburg (Germany),..., or the set of Iranian cities such as Ahvaz and Isfahan,..., or the set of world provinces such as Mazandaran (Iran), Florida (USA),..., or the set of world countries such as Iran, Japan,..., or the set of Iranian provinces such as Mazandaran, Gilan,.... It is evident that as the studied regions become broader (worldwide) and the components of set $\mathrm{A}$ are more detailed (enclosed regions), the estimates would be more reasonable and acceptable. Set A can have a members and $\mathrm{a}_{\mathrm{i}, \mathrm{j}}$ is the $\mathrm{i}^{\text {th }}$ industry in the $\mathrm{j}^{\text {th }}$ region being studied:

$$
A=\left\{j \in \mathbb{N}, j \in[1, . ., a], a_{i, j}\right\}=\left\{a_{i, j}\right\}
$$

Set P: This set, which is related to the type of pollutants, can contain members such as carbon dioxide, carbon monoxide, sulfur dioxide, lead, nitrogen oxides, volatile organic compounds, cyclic aromatic hydrocarbons, etc., and is defined by Eq. (3). It can include $p$ members, where $p_{i, j, k}$ represents pollutant $k$ produced by the $i^{\text {th }}$ industry in the $j^{\text {th }}$ region: 


$$
\mathrm{P}=\left\{\mathrm{k} \in \mathbb{N}, \mathrm{k} \in[1, \ldots, \mathrm{p}], \mathrm{p}_{\mathrm{i}, \mathrm{j}, \mathrm{k}}\right\}=\left\{\mathrm{p}_{\mathrm{i}, \mathrm{j}, \mathrm{k}}\right\}
$$

Care should be taken to normalize the amount of pollutants. Consequently, $\mathrm{p}_{\mathrm{i}, \mathrm{j}, \mathrm{k}, \text { normalized }}$ would mean the $\mathrm{k}^{\text {th }}$ pollutant, produced per unit of product in the $\mathrm{i}^{\text {th }}$ industry in the $\mathrm{j}^{\text {th }}$ region. To calculate $\mathrm{p}_{\mathrm{i}, \mathrm{j}, \mathrm{k}, \mathrm{normalized}}$, the following equation can be used:

$$
\begin{aligned}
& \mathrm{p}_{\mathrm{i}, \mathrm{j}, \mathrm{k}, \mathrm{normalized}}=\left(\text { total } \mathrm{k} \text { pollution in the } \mathrm{a}_{\mathrm{i}, \mathrm{j}}\right) /(\text { total mass } \\
& \text { production of } \mathrm{a}_{\mathrm{i}, \mathrm{j}} \text { ) }
\end{aligned}
$$

Set $\mathrm{M}$ can include $\mathrm{m}$ members, set $\mathrm{A}$ can have a members and set $\mathrm{P}$ can include $\mathrm{p}$ members. Therefore, the number of members in the ecological compatibility set $\mathrm{C}$ would maximally be equal to $m \times a \times p$.

Determination of the ecological compatibility degree

The aim is to determine the ecological compatibility degree of the $\mathrm{i}^{\text {th }}$ industry in producing the $\mathrm{k}^{\text {th }}$ pollutant in the $\mathrm{j}^{\text {th }}$ region. For this purpose, an ecological compatibility set $\mathrm{C}$ is defined, which contains different industries producing various pollutants in different regions. Each member of the set is specified by a membership degree, $\mathrm{C}_{\mathrm{i}, \mathrm{j}, \mathrm{k}}$, which indicates a specific industry $i$, producing a specific pollutant $\mathrm{k}$ in a specific region $\mathrm{j}$ how much compatible with ecology. Eq. (5) is used to determine the ecological compatibility degree of the members in set C. Eq. (5) is the modified equation used by [8].

with the region factor

$$
c_{i, j, k}=\left(\left(\frac{\operatorname{Min}\left\{p_{i, j, k, \text { Normalized }}\right\}}{\left\{P_{i, j, k, \text { Normalized }}\right\}}\right)\left(\frac{G_{k, \text { Critical }}}{G_{k, j}}\right)\right)
$$

Without the region factor

$$
\begin{gathered}
c_{i, j, k}=\left(\frac{\text { Min }\left\{p_{i, j, k, \text { Normalized }}\right\}}{\left\{P_{i, j, k, \text { Normalized }}\right\}}\right) \\
\mathrm{C}=\left\{\mathrm{C}_{\mathrm{i}, \mathrm{j}, \mathrm{k}}\right\}
\end{gathered}
$$

In the above equation, $\mathrm{G}_{\mathrm{k}, \mathrm{j}}$ is the present value of the $\mathrm{k}^{\text {th }}$ pollutant in the $\mathrm{j}^{\text {th }}$ region, which is reported by measuring the pollutant in every region (Air Pollution Control District), and is dependent on the time and location conditions, and $\mathrm{G}_{\mathrm{k}, \text { critical }}$ is the critical value of the same pollutant $k$ in the same region $\mathrm{j}$, which is determined by environmental standards, and is independent on the time and location conditions.

Thus, all industries are ranked uniformly and relatively between 0 and 1 , according to the pollutants they produce and the regions they belong to. Therefore, ecological compatibility degree of 0 for $\mathrm{C}_{\mathrm{i}, \mathrm{j}, \mathrm{k}}$ member indicates an industry $i^{\text {th }}$, located in the $j^{\text {th }}$ region, producing the $\mathrm{k}^{\text {th }}$ pollutant, which is not at all compatible with ecology. On contrary, ecological compatibility degree of 1 for the same member $\mathrm{C}_{\mathrm{i}, \mathrm{j}, \mathrm{k}}$ means that the concerned industry is highly compatible with ecology. Similarly, a ecological compatibility degree between 0 and 1 for $\mathrm{C}_{\mathrm{i}, \mathrm{j}, \mathrm{k}}$ member means that the industry is to some extent compatible with ecology.

If the value of the $\mathrm{k}^{\text {th }}$ pollutant in the $\mathrm{j}^{\text {th }}$ region, $\mathrm{G}_{\mathrm{k}, \mathrm{j}}$, is greater than the critical value, $G_{k, c r i t i c a l}$, the ecological compatibility degree will become smaller because the region coefficient, $G_{k, \text { critical }} / G_{k, j}$, is smaller than one. The lower the ecological compatibility degree; the more difficult it becomes to change conditions to achieve ecological compatibility for the $\mathrm{i}^{\text {th }}$ industry, which is responsible for the production of $\mathrm{k}^{\text {th }}$ pollutant in the $\mathrm{j}^{\text {th }}$ region. On the other hand, when the value of a pollutant in a region is less than its critical value, the region coefficient is larger than one. So, the ecological compatibility degree for some members may be greater than one. Although the membership greater than one has not been defined in fuzzy phenomena, it is meaningful here. The greater the ecological compatibility degree, the easier it becomes to change conditions for ecological compatibility of the desired member.

The most ecological compatible industry is one that has the highest ecological compatibility degree. To determine the most ecological compatible industry, $\mathrm{C}_{\mathrm{i}, \mathrm{j}, \mathrm{k}, \text { Environmental, the }}$ fuzzy maximum rule is used as given below:

$$
\mathrm{C}_{\mathrm{i}, \mathrm{j}, \mathrm{k}, \text { Environmental }}=\operatorname{Max}\left\{\mathrm{C}_{\mathrm{i}, \mathrm{j}, \mathrm{k}}\right\}
$$

In a similar manner, the least ecological compatible industry is the industry that has the smallest ecological compatibility degree. To determine the least ecological compatible industry, $\mathrm{C}_{\mathrm{i}, \mathrm{j}, \mathrm{k}, \text { critical }}$, the fuzzy minimum rule is used as given below:

$$
\mathrm{C}_{\mathrm{i}, \mathrm{j}, \mathrm{k}, \text { Environmental }}=\operatorname{Min}\left\{\mathrm{C}_{\mathrm{i}, \mathrm{j}, \mathrm{k}}\right\}
$$

It may seem that monitoring the pollutants in the set of industries can be misleading because for example, an industry which uses advanced production technologies has a high ecological compatibility degree since the normalized value of pollutants is low. However, the total amount of a pollutant in a given time may be very high, so that the industry practically allocates the bulk of production of the pollutant to itself. The significant question is that if the production volume of a product in modern industrial regions with advanced technologies is reduced, what technology will be used to compensate for the deficit caused by the declining production volume? If the intended technology is not an advanced one, the total amount of the pollutant will further increase. The second term in the parenthesis in Eq. (5), $\mathrm{G}_{\mathrm{k}, \text { critical }} / \mathrm{G}_{\mathrm{k}, \mathrm{j}}$, has been included to present the total amount of the variable pollutant over time in a given region.

Determination of the ecological compatibility degree in pyrometallurgy industries: A case study

In this case study, data on four pyrometallurgy industries, namely iron and steel production industry, aluminium production industry, lead production industry, and zinc production industry, published in December 2005, has been used. Accordingly, set $\mathrm{M}$, which represents the industries, contains four members, i.e., $\mathrm{m}=4$. Similarly, for set A, representing the regions in which pollutants are produced, four countries were considered; one in the Middle East, one in the Far East, one in America, and one in Europe. Therefore, set $\mathrm{A}$ will have four members, i.e., $\mathrm{a}=4$. In order to avoid prejudice and bias, names of countries studied have not been 
mentioned. Also, to simplify and integrate the data, only one air pollutant, namely carbon dioxide, has been considered in this study, which means set $\mathrm{P}$, which represents the set of the studied pollutants, has only one member, i.e., $p=1$. Therefore, the maximum number of members of set $\mathrm{C}$ will be equal to $4 \times 4 \times 1=16$.

Table 1. The ecological compatibility degrees for industries in different regions, with and without the region factor.

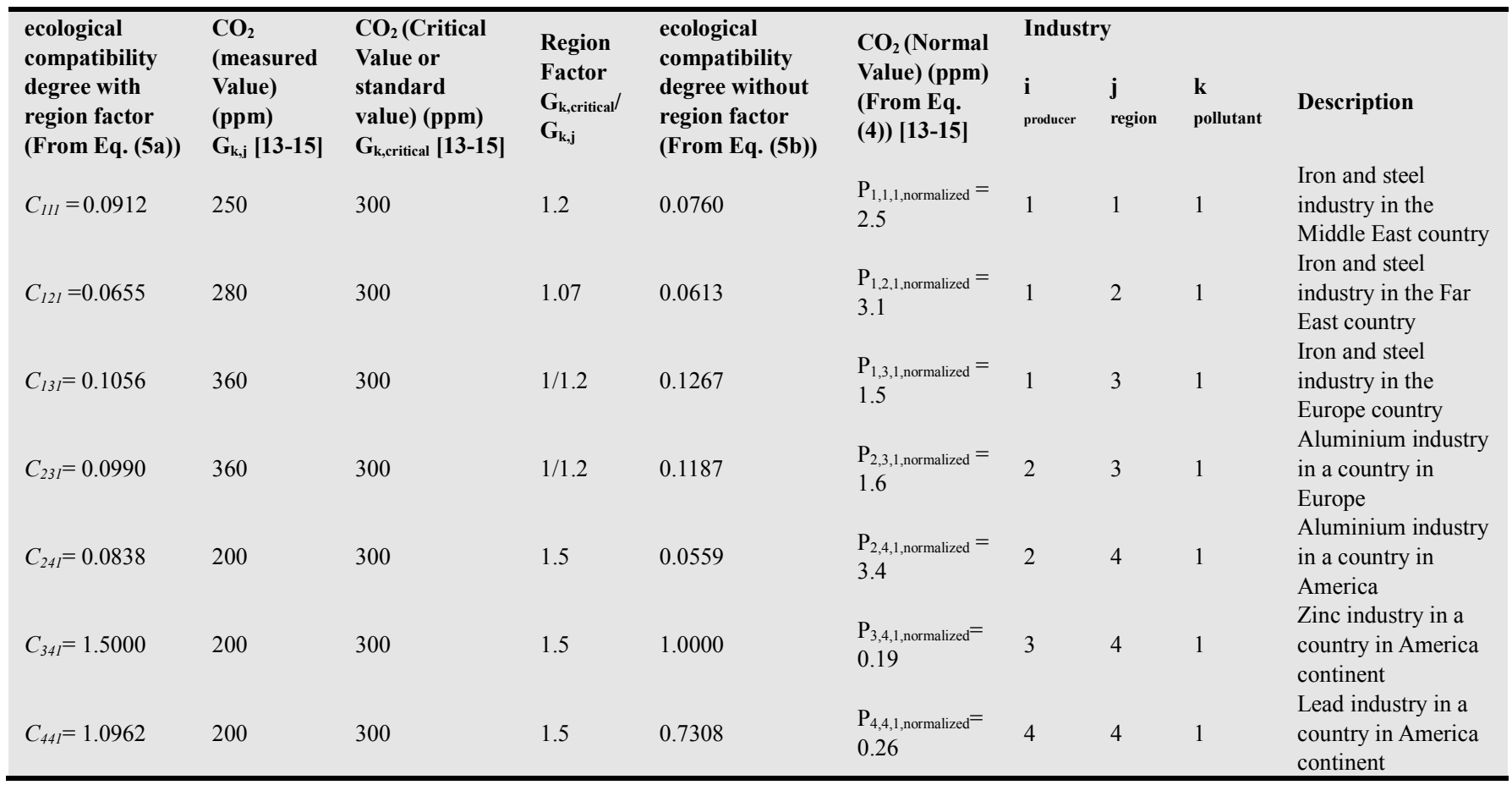

Ecological compatibility degree in the iron and steel production industry

Major pollutants in iron and steel production industry are: (i) gaseous pollutants: carbon dioxide, greenhouse gases, carbon monoxide, sulphur dioxide, nitrogen oxides, chloride and fluoride, volatile organic compounds, cyclic aromatic hydrocarbons, dioxins, (ii) solid pollutants: dust, heavy metals such as sponge iron, zinc, cadmium, lead, nickel, mercury, magnesium, and cream, soot, (iii) liquid pollutants: sewage and waste water from the production process, which mainly contain suspended particles, dust and lubricant materials. Sound pollution in the iron and steel production units is due to the handling of steel products and scrap, cooling fans, electric arc melting process in furnace, fuel torches, shaping and cutting tools and transport [1]. To simplify and integrate the data, only one air pollutant, namely carbon dioxide, has been considered, which means $\mathrm{k}=1$.

Ecological compatibility degree in the aluminium production industry

Major pollutants in aluminium production industry area carbon dioxide in the air, hexa fleoromethane, tetra fleoromethane as gas and dust, sulphur dioxide, nitrogen dioxide and mercury [9]. To simplify and integrate the data, only one air pollutant, namely carbon dioxide, has been considered, which means $\mathrm{k}=1$.

Ecological compatibility degree in zinc production industry

Major pollutants in zinc production industry are carbon dioxide in the air, sulphur compounds and nitrogen oxides [10, 11]. To simplify and integrate the data, only one air pollutant, namely carbon dioxide, has been considered, which means $\mathrm{k}=1$. Ecological compatibility degree in the lead production industry

Major pollutants in zinc production industry are carbon dioxide in the air, lead in air and water, sulphur compounds and nitrogen oxides [12]. To simplify and integrate the data, only one air pollutant, namely carbon dioxide, has been considered, which means $\mathrm{k}=1$.

Calculating the ecological compatibility degree in pyrometallurgy industries

The quantity of carbon dioxide in different regions, $\mathrm{G}_{\mathrm{k}, \mathrm{j}}$, is listed in Table 1. Thus, the region coefficient has different values for different members, $\mathrm{C}_{\mathrm{i}, \mathrm{j}, \mathrm{k}}$, in the ecological compatibility set.

$\mathrm{M}=\left\{\mathrm{i} \in \mathbb{N}, \mathrm{i} \in[1,2,3,4], \mathrm{m}_{\mathrm{i}}\right\} \rightarrow \mathrm{M}=\{$ Iron and steel production, Aluminium production, Zinc production, Lead production $\}$

$\mathrm{A}=\left\{\mathrm{j} \in \mathbb{N}, \mathrm{j} \in[1,2,3,4], \mathrm{a}_{\mathrm{i}, \mathrm{j}}\right\} \rightarrow \mathrm{A}=\{$ a country in America, one in Europe, one in the Middle East, one in the Far East

$$
\mathrm{P}=\left\{\mathrm{k} \in \mathbb{N}, \mathrm{k} \in[1], \mathrm{P}_{\mathrm{i}, \mathrm{j}, \mathrm{k}}\right\} \rightarrow \mathrm{P}=\left\{\mathrm{CO}_{2}\right\}
$$

\section{Results and Discussion}

According to Eq. (1) to (5) and data from Table 1, values of the ecological compatibility degree, with and without the region coefficient, have been calculated and are listed in the same Table 1.

According to Eq. (6), considering the region coefficient, the most ecologically compatible member in set $\mathrm{C}$, namely $\mathrm{C}_{341}$, 
which produces carbon dioxide, with an ecological compatibility degree of 1.5000 (obtained as follows), is the Zinc production industry, in a country in the American continent during the period December 2005:

$$
\begin{aligned}
& \mathrm{C}_{\text {Max }}=\{0.0912,0.0655,0.1056,0.0990,0.0838,1.5000 \text {, } \\
& 1.0962\}=\mathrm{C}_{341}=1.5000
\end{aligned}
$$

According to Eq. (7), including the region coefficient, the least ecologically compatible member in set $\mathrm{C}$, namely $\mathrm{C}_{121}$, which produces carbon dioxide, with an ecological compatibility degree of 0.0655 (obtained as follow), is the steel industry, in a country in the Far East, during the period December 2005:

$$
\begin{gathered}
\mathrm{C}_{\mathrm{Min}}=\{0.0912,0.0655,0.1056,0.0990,0.0838,1.5000, \\
1.0962\}=\mathrm{C}_{121}=0.0655
\end{gathered}
$$

The ecological compatibility degrees, with and without the area effect, for all regions and industries producing carbon dioxide during the period December 2005, have been compared in Fig. 2.

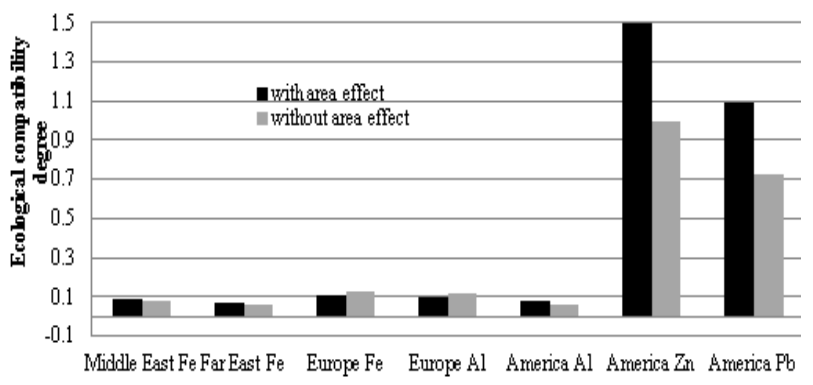

Figure 2. Ecological compatibility degrees, with and without the area effect, for all regions and industries producing carbon dioxide during the period December 2005.

\section{Conclusions}

In December 2005, in those parts of the world where the amount of carbon dioxide was greater than the maximum allowable limit, i.e., $G_{k, c r i t i c a l} / G_{k, j}$ was greater than 1 , emission of even a small quantity of addition carbon dioxide would be dangerous. However, it is practically impossible to stop the production of steel and aluminium because many industries depend on these products for their operation. In addition, for different members, value of $G_{k, \text { critical }} / G_{k, j}$ is different in different regions. This means in a region with lower production of carbon dioxide, conditions for the production of these metals is more favourable. Therefore, it is necessary to determine the industry, and the related region, with the least ecological compatibility in the production of carbon dioxide. In other words, it must be determined that which industry, in which region, has more difficulties in changing its manufacturing conditions for attaining higher ecological compatibility degree in the production of carbon dioxide.

In December 2005, in the set of ecological compatibility, $\mathrm{C}_{\mathrm{i}, \mathrm{j}, \mathrm{k}}$, member $\mathrm{C}_{241}$, namely the aluminium industry in a country in the American continent, producing carbon dioxide, without taking into account the region coefficient, has an ecological compatibility degree of 0.0559 , has the most critical condition in producing air pollutant carbon dioxide. If the region coefficient is taken into consideration, steel industry in a country in the Far East, namely member $\mathrm{C}_{121}$, in the same period of year, with an ecological compatibility degree of 0.0655 , has the most critical conditions in producing air pollutant, carbon dioxide.

Therefore, more focus should be put on controlling carbon dioxide emissions in the steel industry in the Far East country. Control methods could include more training for the manpower, the use of new and rehabilitated units, innovation in cleaner technologies, ecological cleanup (such as tree planting); the use of alternative materials to reduce consumption of steel and steel products. By taking into account the region coefficient, and considering the parameters studied, the ecological compatibility degree in other industries in ascending order can be put as the followings:

- Aluminium industry in a country in American continent, $\mathrm{C}_{241}$, with the ecological compatibility degree of 0.0838 , is in the second priority for investigation.

- Iron and steel industry in a country in the Middle East, $\mathrm{C}_{111}$, with the ecological compatibility degree of 0.0912 , is in the third priority for investigation.

- Aluminium Industry in a country in Europe, $\mathrm{C}_{231}$, with the ecological compatibility degree of 0.0990 , is in the fourth priority for investigation.

- Iron and steel industry in a country in Europe, $\mathrm{C}_{131}$, with the ecological compatibility degree of 0.1056 , is in the fifth priority for investigation.

- Lead industry in a country in American continent, $\mathrm{C}_{441}$, with the ecological compatibility degree of 1.0962 , is in the sixth priority for investigation.

- Zinc industry in a country in American continent, $\mathrm{C}_{341}$, with the ecological compatibility degree of 1.5000 , is in the seventh priority for investigation.

\section{Suggestions}

1) In this study, for the sake of simplification, only a limited number of industries, regions, and pollutants has been studied. On increasing the number of members of the various sets namely sets of pollutants, industries and regions at different times, a larger range of parameters can be monitored, which will add to the accuracy of the results.

2) Although in this study the proposed model has been used to monitor the pollutants resulting from the operation of metal production industry, the same model can be applied for other industries and pollutants in any other region in the world.

\section{References}

[1] S.E. Vahdat and A. Pournaghi, "The Model for Monitoring of Pollutants Located in Different Regions", Management Science and Practice, Vol. 1, Iss. 1, PP. 8-13, 2013. 
[2] M.H. Sowlat, H. Gharibi, M. Yunesian, M. Tayefeh Mahmoudi and S. Lotfi, "A novel fuzzy-based air quality index (FAQI) for air quality assessment", Atmospheric Environment, Vol. 45, pp. 2050-2059, 2011.

[3] R. Mintz, B.R. Young and W.Y. Svrcek, "Fuzzy logic modeling of surface ozone concentrations", Journal of Computers and Chemical Engineering, Vol. 29,pp. 2049-2059, 2005.

[4] O.M. Pokrovsky, R.H.F. Kwok and C.N. Ng, "Fuzzy logic approach for description of meteorological impacts on urban air pollution species: a Hong Kong case study", Computers and Geosciences, Vol. 28, pp. 119-127, 2002.

[5] A. Astel, "Chemometrics based on Fuzzy logic principles in environmental studies", Talanta, Vol. 72, pp. 1-12, 2007.

[6] P.H. Chen, J.-H. Lai and C.-T. Lin., "Application of Fuzzy control to a road tunnel ventilation system", Fuzzy Sets and Systems, Vol. 100, pp. 9-28, 1998.

[7] Y. Icaga, "Fuzzy evaluation of water quality classification", Ecological Indicators, Vol. 7, pp. 710-718, 2007.

[8] S. E. Vahdat and F.M. Nakhaee, "Air Pollution Monitoring using Fuzzy Logic in Industries", F. Nejadkoorki, Ed. Rijeka, Croatia: InTech publication, 2011.
[9] (2005) The Aluminum society website. [Online]. Available: http://www.world-aluminium.org

[10] K. Lamm K., "The CO2 - Story - A Fairy - Tale - (Or a Nightmare?)," Lead Zinc 2010, MetSoc COM 2010, A john and Sons Inc., 2010, p. 953.

[11] D. Moradkhani, B. Sedaghat, A. Rashtchi and A. Khodadadi, "Heavy metal pollution potential of zinc leach residues discarded in IZMDC", Lead Zinc 2010, MetSoc, COM 2010, A john and Sons Inc., 2010, p. 141.

[12] (2005) The Lead society website. [Online]. Available: http://www.lead.org

[13] Geir O. Braathen, Ed., An overview of the 2005: Antarctic Ozone Hole, WMO Global Ozone Research and Monitoring Project, Word Meteorological Organizationreport no. 49 (WMO TD no. 1312), Maryland, USA, 2005, vol. 49.

[14] (2005) The EPA website. [Online]. Available: http://epa.gov/air/emissions/index.htm

[15] (2005) The SDAPCD website. [Online]. Available: http://www.sdapcd.org. 